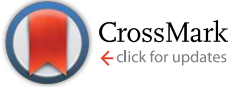

Cite this: Chem. Sci., 2017, 8, 2931

Received 19th December 2016 Accepted 31st January 2017

DOI: $10.1039 / \mathrm{c} 6 \mathrm{sc05551f}$

rsc.li/chemical-science

\section{Zwitterionic amidinates as effective ligands for platinum nanoparticle hydrogenation catalysts $\dagger$}

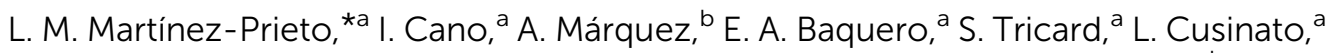 \\ I. del Rosal, ${ }^{a}$ R. Poteau, ${ }^{a}$ Y. Coppel, ${ }^{c}$ K. Philippot, ${ }^{c}$ B. Chaudret, ${ }^{a}$ J. Cámpora ${ }^{\star b}$ \\ and P. W. N. M. van Leeuwen ${ }^{\star a}$
}

Ligand control of metal nanoparticles (MNPs) is rapidly gaining importance as ligands can stabilize the MNPs and regulate their catalytic properties. Herein we report the first example of Pt NPs ligated by imidazoliumamidinate ligands that bind strongly through the amidinate anion to the platinum surface atoms. The binding was established by ${ }^{15} \mathrm{~N}$ NMR spectroscopy, a precedent for nitrogen ligands on MNPs, and XPS. Both monodentate and bidentate coordination modes were found. DFT showed a high bonding energy of up to $-48 \mathrm{kcal} \mathrm{mol}^{-1}$ for bidentate bonding to two adjacent metal atoms, which decreased to $-28 \pm 4$ $\mathrm{kcal} \mathrm{mol}^{-1}$ for monodentate bonding in the absence of impediments by other ligands. While the surface is densely covered with ligands, both IR and ${ }^{13} \mathrm{C}$ MAS NMR spectra proved the adsorption of CO on the surface and thus the availability of sites for catalysis. A particle size dependent Knight shift was observed in the ${ }^{13} \mathrm{C}$ MAS NMR spectra for the atoms that coordinate to the surface, but for small particles, $\sim 1.2 \mathrm{~nm}$, it almost vanished, as theory for MNPs predicts; this had not been experimentally verified before. The Pt NPs were found to be catalysts for the hydrogenation of ketones and a notable ligand effect was observed in the hydrogenation of electron-poor carbonyl groups. The catalytic activity is influenced by remote electron donor/acceptor groups introduced in the aryl- $N$-substituents of the amidinates; $p$-anisyl groups on the ligand gave catalysts several times faster the ligand containing $p$-chlorophenyl groups.

\section{Introduction}

The interest in metal nanoparticles (MNPs) is growing fast in both the academic and industrial community thanks to their applications in multiple fields such as sensors, medicine, optoelectronics and catalysis. ${ }^{1}$ In particular, MNPs have a high catalytic activity in some specific transformations like hydrogenation, polymerization, oxidation and $\mathrm{C}-\mathrm{C}$ coupling reactions. ${ }^{2}$ Their high potential in catalysis arises from their particular electronic configuration and large surface area, and the potential to combine the advantages of homogeneous and heterogeneous catalysts. The stability and activity of MNPs are strongly influenced by the ligands used as stabilizers, which are able to modify their surface properties. ${ }^{3}$

The exploration of new families of ligands capable to stabilize MNPs and modify their reactivity is always a challenge. In a recent

${ }^{a}$ LPCNO, Laboratoire de Physique et Chimie des Nano-Objets, UMR5215 INSA-CNRS-UPS, Institut des Sciences Appliquées, 135, Avenue de Rangueil, F-31077 Toulouse, France.E-mail:vanleeuw@insa-toulouse.fr; Immartin@insa-toulouse.fr

${ }^{b}$ Instituto de Investigaciones Quimicas, CSIC-Universidad de Sevilla, C/Américo Vespucio, 49, 41092 Sevilla, Spain. E-mail: campora@iiq.csic.es

${ }^{c}$ CNRS, LCC (Laboratoire de Chimie de Coordination), Université de Toulouse, UPS, INPT, 205 route de Narbonne, BP 44099, F-31077-Toulouse Cedex 4, France

$\dagger$ Electronic supplementary information (ESI) available. See DOI: $10.1039 / \mathrm{c} 6 \mathrm{sc} 05551 \mathrm{f}$ publication, the betaine-type adduct of N-heterocyclic carbenes (NHCs) and carbodiimides (Scheme 1), in particular 1,3-dicyclohexylimidazolium-2-di- $p$-tolylcarbodiimide $\left(\mathrm{ICy} \cdot{ }^{(p \text {-tol })} \mathrm{NCN}\right)$, was identified as an effective ligand to produce ultra-small ruthenium nanoparticles (Ru NPs) with a size ca. $1 \mathrm{~nm} .{ }^{4}$ Due to their zwitterionic structure, the nitrogen atoms present a large electrondonor capability and coordinate strongly to transition metals. The coordination chemistry of such imidazolium-amidinate ligands has been investigated a short while ago by some of us. ${ }^{5}$ In analogy with amidinates, which frequently coordinate in a $\mu^{2}-\kappa^{1} \mathrm{~N}, \kappa^{1} \mathrm{~N}^{\prime}$ bridging mode, ICy ${ }^{(p-\text { tol })} \mathrm{NCN}$ forms multi-bridged binuclear "paddlewheel" complexes of copper(I). Besides, small

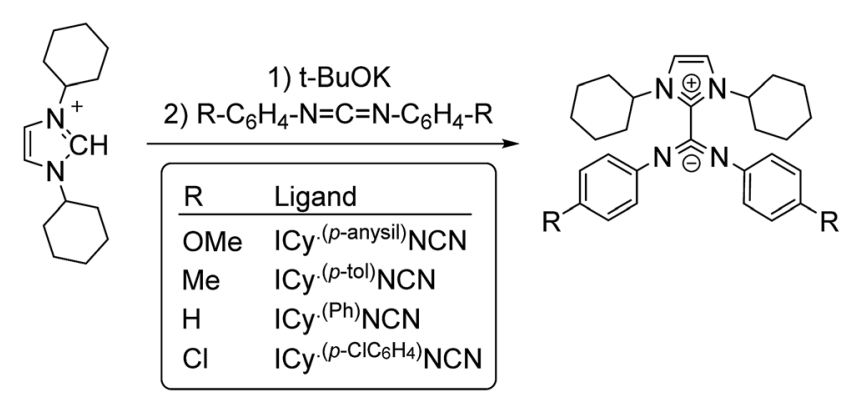

Scheme 1 Synthesis of zwitterionic imidazolium-amidinate ligands. 
changes on the $\mathrm{N}$-substituents give us the possibility to modify their electronic properties. For example, introducing electron acceptor/donor moieties (-Cl or -OMe) in these pending groups enables us to modulate the surface properties of MNPs.

By the use of spectroscopic techniques, such as NMR or FTIR, the coordination and dynamics of surface ligands of MNPs can be properly investigated. Recently, the coordination of NHC ligands to ruthenium and platinum nanoparticles was investigated by solid-state NMR spectroscopy. ${ }^{6}$ Moreover, NMR studies on $\mathrm{Ru}$ and $\mathrm{Pt}$ NPs stabilized by hexadecylamine (HDA) confirmed that Pt displays a Knight shift (due to the presence of free electrons on the surface) which is much stronger than that of Ru. ${ }^{7}$ This effect was also observed in Pt NPs of 1.2 and $2.0 \mathrm{~nm}$, for which the different electronic states resulted in unequal magnitudes of Knight shift. ${ }^{8}$ However, ultra-small Pt NPs $(<1 \mathrm{~nm})$ behave as molecular species without free electrons and no Knight shift occurs. ${ }^{9}$ Another important instrument to characterize the surface of the nanoparticles is the use of carbon monoxide (CO) as a probe molecule, since $\mathrm{CO}$ coordination can be especially useful to determine the active sites. ${ }^{\mathbf{8 , 1 0}}$

Theoretical calculations are of great importance in order to shed more light on experimental data, as for example to secure the assignment of experimental solid state NMR spectra or for the calculation of properties that cannot be measured experimentally. ${ }^{11}$ In the context of the nanoparticle surface chemistry, the theoretical calculations provide detailed information not only on the coordination mode of the species bound to the nanoparticle surface, ${ }^{\mathbf{1 2}}$ but also on the chemical reactions that may take place on these surfaces. ${ }^{\mathbf{1 3}}$

Ligand-stabilized metal NPs are effective catalysts for hydrogenation of olefin, carbonyl and nitro functionalities, as well as aromatics. ${ }^{\mathbf{1 4}}$ In this context, Pt NPs have shown important chemoselectivities in hydrogenation of olefin ${ }^{\mathbf{6 b}, 15}$ and nitro groups. ${ }^{16}$ Herein we present a series of Pt NPs ligated by imidazolium-amidinates (ICy. ${ }^{(\mathrm{Ar})} \mathrm{NCN}$ ) which exhibit an exciting ligand effect in the hydrogenation of carbonyl groups when electron donor/acceptor groups are introduced in the $\mathrm{N}$ substituents. These Pt NPs were characterized by the state-ofthe-art techniques (TEM, HRTEM, WAXS, TGA and EA) and studied their surface chemistry through the coordination of $\mathrm{CO}$ (FT-IR and solid state MAS NMR). Here a clear correlation between the Knight shift of adsorbed CO and the NPs size was observed. In addition, the coordination of the imidazoliumamidinate ligands was investigated in Pt and Ru NPs by XPS, solid state ${ }^{15} \mathrm{~N}$ MAS NMR and DFT calculations.

\section{Results and discussion}

\section{Synthesis and characterization of Pt NPs}

Zwitterionic adducts of $N, N$-dicyclohexylimidazolidene and diarylcarbodiimide (ICy. ${ }^{(\mathrm{Ar})} \mathrm{NCN} ; \mathrm{Ar}=\mathrm{Ph}, p$-tol, $p$-anisyl, $p$ - $\left.\mathrm{ClC}_{6} \mathrm{H}_{4}\right)$ were prepared similarly to previously reported betaine-type adducts, ${ }^{4,5}$ by reaction of $\mathrm{N}$-heterocyclic carbene (ICy) and a suitable carbodiimide, namely bis(4-methylphenyl) methanediimine $\left({ }^{(p-\text { tol })} \mathrm{NCN}\right)$, bis(4-methoxyphenyl)methanediimine $\left({ }^{(p \text {-anisyl })} \mathrm{NCN}\right)$, bis(4-chlorophenyl)methanediimine $\left({ }^{\left(p-\mathrm{ClC}_{6} \mathrm{H}_{4}\right)} \mathrm{NCN}\right)$ and ${ }^{15} \mathrm{~N}$-labelled bis-phenylmethanediimine $\left({ }^{(\mathrm{Ph})} \mathrm{NC}^{15} \mathrm{~N}\right)$ (Scheme 1). Non-commercial carbodiimides were obtained in high yields by desulphurization of the corresponding thioureas with $\mathrm{I}_{2}$ in the presence of $\mathrm{NEt}_{3}$, using literature procedures. ${ }^{17}$ The symmetric thioureas $\left(p-\mathrm{RC}_{6} \mathrm{H}_{4}\right)_{2} \mathrm{C}=\mathrm{S}(\mathrm{R}=\mathrm{OMe}, \mathrm{Cl})$ were readily synthesized from thiophosgene and the corresponding aniline. ${ }^{15} \mathrm{~N}$-labeled diphenylthiourea used to prepare ${ }^{(\mathrm{Ph})} \mathrm{NC}^{15} \mathrm{~N}$ was obtained from phenylisothiocyanate and aniline. ${ }^{17 a}$ With this method we expected to form the singly ${ }^{15} \mathrm{~N}$-labeled product, but the ESI-MS spectrum of the thiourea showed a signal for the corresponding anion of which the isotopic pattern was consistent with a statistical $1: 2: 1$ mixture of the normal $\left({ }^{14} \mathrm{~N}_{2}\right)$, monolabeled $\left({ }^{14} \mathrm{~N}^{15} \mathrm{~N}\right)$ and doubly-labeled isotopologues $\left({ }^{15} \mathrm{~N}_{2}\right)$. As shown in Scheme S1 (see ESI, Section S1 $\dagger$ ), scrambling of the ${ }^{15} \mathrm{~N}$ label indicates that aniline addition to phenylisothiocyanate is reversible.

Most of Pt NPs reported in this paper were conveniently obtained by reaction of tris(2-norbornene)platinum(0) $\left[\mathrm{Pt}(\mathrm{NBE})_{3}\right]$ in THF under 3 bar $\mathrm{H}_{2}$ in the presence of the corresponding imidazolium-amidinate ligand (Scheme 2). Herein we report for the first time the use of $\mathrm{Pt}(\mathrm{NBE})_{3}$ as metallic precursor in the synthesis of Pt NPs by the organometallic approach. The advantages of $\mathrm{Pt}(\mathrm{NBE})_{3}$ versus the typical Pt precursors [tris(dibenzylideneacetone)diplatinum (0); $\mathrm{Pt}_{2}(\mathrm{DBA})_{3}$ or dimethyl(1,5cyclooctadiene)platinum(II); $\left.\mathrm{Pt}\left(\mathrm{CH}_{3}\right)_{2}(\mathrm{COD})\right]$ are evident. ${ }^{7,8,18}$ First, the purification of the obtained nanoparticles is simplified as the norbornane formed during the decomposition can be rapidly eliminated under vacuum and makes it this complex a "clean" precursor. And, second, the highly reactive $\mathrm{Pt}(\mathrm{NBE})_{3}$ requires less time for the formation of Pt NPs under $\mathrm{H}_{2}$. Thus, the use of $\mathrm{Pt}(\mathrm{NBE})_{3}$ as precursor is advantageous both for the formation and purification of Pt NPs. Different amounts of ICy. ${ }^{(p-t o l)} \mathrm{NCN}$ were employed for the synthesis of Pt NPs, specifically $0.1,0.2$ and 0.5 molar equiv. $\left(\mathrm{Pt} / \mathrm{ICy} \cdot\left({ }^{p}\right.\right.$-tol $) \mathrm{NCN}_{0.1}, \mathrm{Pt} /$ ICy ${ }^{(p-\text { tol })} \mathrm{NCN}_{0.2}$ and Pt/ICy $\left.\cdot{ }^{\left({ }^{-} \text {tol }\right)} \mathrm{NCN}_{0.5}\right)$, with the aim to obtain different sizes and reactivities. Indeed, Transmission Electronic Microscopy (TEM) micrographs of Pt/ICy. ${ }^{(p \text {-tol })} \mathrm{NCN}_{0.1}, \mathrm{Pt} /$ ICy $\cdot{ }^{(p-\text { tol })} \mathrm{NCN}_{0.2}$ and Pt/ICy $\cdot{ }^{(p-t o l)} \mathrm{NCN}_{0.5}$ exhibit Pt NPs with a mean diameter of $2.3(0.3), 2.1(0.2)$ and $1.9(0.4) \mathrm{nm}$ respectively (Fig. 1), and one observes a correlation between the quantity of ligand and the average size of the obtained NPs; more ligand leads to smaller particles. This behavior was already observed in our previous work with $\mathrm{Ru} / \mathrm{ICy} \cdot{ }^{(p-\text { tol })} \mathrm{NCN},{ }^{4}$ and also with other type of ligands, such as NHCs, ${ }^{6 a, 19}$ aminosilanes $^{20}$ and sulfonated diphosphines. ${ }^{21} \mathrm{Pt} / \mathrm{ICy} \cdot{ }^{(p-t o l)} \mathrm{NCN}_{0.1}$

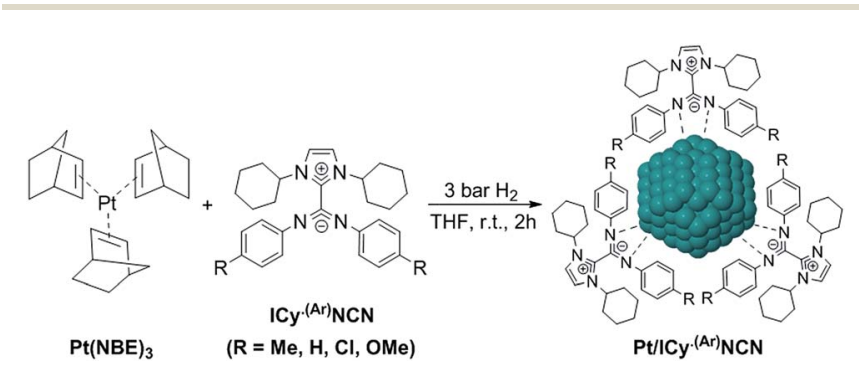

Scheme 2 Synthesis of platinum nanoparticles using imidazoliumamidinate ligands as stabilizers. 


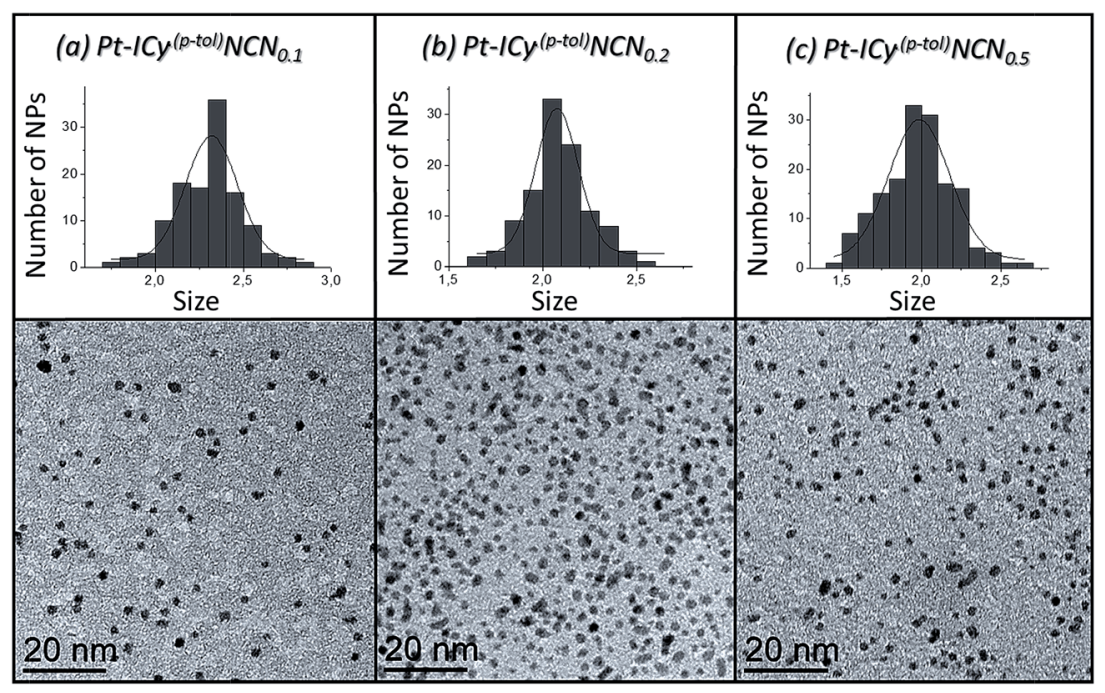

Fig. 1 TEM images and size histograms of (a) Pt/ICy $\cdot{ }^{(p-t o l)} \mathrm{NCN}_{0.1}$, (b) Pt/ICy. $\cdot{ }^{(p-t o l)} \mathrm{NCN}_{0.2}$ and (c) Pt/ICy. $\cdot{ }^{(p-t o l)} \mathrm{NCN} \mathrm{N}_{0.5}$.

and $\mathrm{Pt} / \mathrm{ICy} \cdot{ }^{(p-t o l)} \mathrm{NCN}_{0.2}$ micrographs revealed NPs that are very well distributed and monodisperse in size, while the image for $\mathrm{Pt} / \mathrm{ICy} \cdot{ }^{(p-t o l)} \mathrm{NCN}_{0.5}$ showed a worse dispersion. For an unknown reason, the range of sizes of these NPs increases with the amount of ligand, while the monodispersity is lost.

High resolution TEM (HRTEM) micrographs of Pt/ ICy ${ }^{(p \text {-tol) }} \mathrm{NCN}_{0.2}$ show crystalline Pt NPs (Fig. 2), displaying the face centered cubic (fcc) structure typical of bulk Pt. Fast Fourier Transformation (FFT) applied to the image of Fig. 2 revealed the reflections corresponding to the (111), (200) and (111) atomic planes.

Wide-Angle X-ray Scattering (WAXS) analyses performed on solid samples of $\mathrm{Pt} / \mathrm{ICy} \cdot{ }^{(p \text {-tol })} \mathrm{NCN}_{0.1}, \mathrm{Pt} / \mathrm{ICy} \cdot{ }^{(p \text { tol })} \mathrm{NCN}_{0.2}$ and $\mathrm{Pt} /$ ICy $\cdot{ }^{(p-\text { tol })} \mathrm{NCN}_{0.5}$ confirmed the crystallinity of these Pt NPs, which retain the fcc structure (see ESI, Fig. S17-S19†). The coherence lengths indicated by the Radial Distribution Function (RDF) resultant from WAXS analysis are slightly higher than the mean diameters determined by TEM. WAXS analysis revealed a coherence length of $2.5 \mathrm{~nm}$ for Pt/ICy. ${ }^{(p-t o l)} \mathrm{NCN}_{0.1}, 2.2 \mathrm{~nm}$ for Pt/ ICy. ${ }^{(p-\text { tol })} \mathrm{NCN}_{0.2}$, and $2.1 \mathrm{~nm}$ for $\mathrm{Pt} / \mathrm{ICy} \cdot{ }^{(p-\text { tol })} \mathrm{NCN}_{0.5}$, while the

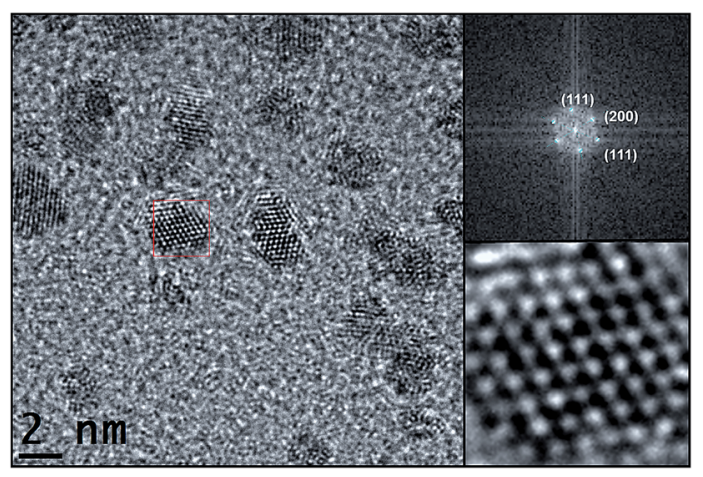

Fig. 2 HRTEM image of Pt/lCy. ${ }^{(p-t o l)} \mathrm{NCN}_{0.2}$ (left, right bottom) and fast Fourier transformation analysis (right, top) with the planar reflections. mean diameters observed by TEM were $2.3,2.1$ and $1.9 \mathrm{~nm}$, respectively.

The Pt NPs were obtained in acceptable yields $(60-70 \%$; based on Pt), and the metal content was determined by thermogravimetric analysis (TGA). The Pt content was $90.1 \%$ for Pt/ ICy $\cdot{ }^{(p \text {-tol })} \mathrm{NCN}_{0.1}, 77.3 \%$ for Pt/ICy. ${ }^{(p \text {-tol })} \mathrm{NCN}_{0.2}$, and $60.1 \%$ for $\mathrm{Pt} / \mathrm{ICy} \cdot{ }^{(p-t o l)} \mathrm{NCN}_{0.5}$. Moreover, elemental analysis (EA) of the NPs revealed that the amounts of $\mathrm{C}, \mathrm{H}$ and $\mathrm{N}$ are in good agreement with the ratio of these elements in the ligand (C, $79.25 \% ; \mathrm{H}, 8.42 \% ; \mathrm{N}, 12.32 \%$ ), suggesting that the imidazolium-amidinate ligand remains intact at the platinum surface (see ESI, Table S1 $\dagger$ ). It is important to mention that the $\mathrm{Pt}: \mathrm{L}$ ratio in $\mathrm{Pt} / \mathrm{ICy} \cdot{ }^{(p-t o l)} \mathrm{NCN}_{0.5}$ shows a large quantity of coordinated ligand at the platinum surface, as the number of ICy. ${ }^{(p-t o l)} \mathrm{NCN}$ molecules is approximately half of the surface atoms ( $\mathrm{Pt}_{\text {surface }} \sim 50 \%$ of $\left.\mathrm{Pt}_{\text {total }}\right)$.

\section{Surface studies}

The surface chemistry of Pt/ICy. ${ }^{(p-\text { tol })} \mathrm{NCN}$ NPs was studied by Fourier transform infrared (FT-IR) and magic angle spinning solid-state ${ }^{13} \mathrm{C}$ and ${ }^{15} \mathrm{~N}$ NMR (MAS-NMR) with and without cross-polarization (CP). $\mathrm{CO}$ was used as a probe molecule as it is well known that coordination of $\mathrm{CO}$ allows the identification of different available surface sites on metal nanoparticles. ${ }^{10,22}$ Commonly, $\mathrm{CO}$ is adsorbed onto the metal surface either in a bridging (COb) or in a terminal (COt) mode. Fig. 3 shows attenuated total reflectance (ATR) FT-IR spectra of Pt/ ICy $\cdot{ }^{(p-t o l)} \mathrm{NCN}$ NPs after bubbling CO during $5 \mathrm{~min}$ in a THF solution. The FT-IR spectrum of Pt/ICy. ${ }^{(p-t o l)} \mathrm{NCN}_{0.1}$ [Fig. 3(a)] presents two distinct bands, at $1845 \mathrm{~cm}^{-1}$ and $2038 \mathrm{~cm}^{-1}$, which can be respectively attributed to $\mathrm{CO}$ coordinated on the Pt surface in a bridging (COb) and in a terminal mode (COt). The stretching band attributed to $\mathrm{COb}$ is very intense, evidencing that a large part of the $\mathrm{CO}$ is coordinated in a bridging mode. Analogous stretching vibrations for adsorbed $\mathrm{CO}$ were previously observed in Pt(111) crystal surfaces and Pt NPs. ${ }^{23}$ The IR 
(a)

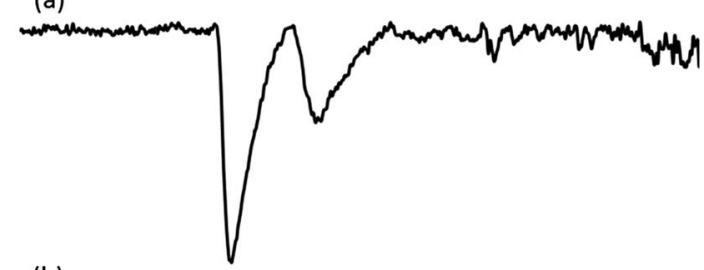

(b)

spectrum of $\mathrm{Pt} / \mathrm{ICy} \cdot{ }^{(p-t o l)} \mathrm{NCN}_{0.2}$ displays similar frequencies at $1816 \mathrm{~cm}^{-1}$ and $2032 \mathrm{~cm}^{-1}$, but here the ratio $\mathrm{COt} / \mathrm{COb}$ has increased [Fig. 3(b)] in comparison with the previous one. This trend persists for $\mathrm{Pt} / \mathrm{ICy} \cdot{ }^{(p-\text { tol })} \mathrm{NCN}_{0.5}$, and the intensities of $\mathrm{CO}$ bands (1808 and $2032 \mathrm{~cm}^{-1}$ ) decrease in relation to the characteristic $\mathrm{C}=\mathrm{N}$ absorption frequencies of the amidinate ligand at 1630 and $1598 \mathrm{~cm}^{-1}$ [Fig. 3(c)] Here we observe an evident relation between the $\mathrm{COt} / \mathrm{COb}$ ratio and the amount of ligand used. We think that both the size and the presence of more ligand on the surface increase the amount of COt at the cost of COb, such that $1.9 \mathrm{~nm} \mathrm{Pt} / \mathrm{ICy} \cdot{ }^{(p-t o l)} \mathrm{NCN}_{0.5}$ NPs contains mostly COt. It is noteworthy that when we decrease the amount of ICy. ${ }^{(p-t o l)} \mathrm{NCN}$ from 0.5 to 0.1 equiv., we observe a slight shift of the CO bands to higher frequency (from 1808 to $1845 \mathrm{~cm}^{-1}$ for COb and from 2032 to $2038 \mathrm{~cm}^{-1}$ for COt). This behavior is in agreement with a higher surface coverage of $\mathrm{CO}$ in $\mathrm{Pt} / \mathrm{ICy} \cdot{ }^{(p \text {-tol })} \mathrm{NCN}_{0.1}$, which removes more electron density from the Pt surface (see ESI, Fig. S25†). The displacement of the CO stretching frequency in relation with the quantity of CO has been previously described for surfaces and MNPs. ${ }^{8,23 b, 24}$

Thanks to FT-IR we obtained the first indication about the coordination mode of the imidazolium-amidinate ligand. Comparing the IR spectra of the ligand ICy. ${ }^{(p-t o l)} \mathrm{NCN}$ (see ESI, Fig. S20†) and the particle Pt/ICy. ${ }^{(p-t o l)} \mathrm{NCN}_{0.5}$ (see ESI, Fig. S26 $\dagger$ ), we observed a clear $100 \mathrm{~cm}^{-1}$ displacement of the strong stretching $\mathrm{C}=\mathrm{N}$ bands, from 1530 and $1495 \mathrm{~cm}^{-1}$ to 1630 and $1598 \mathrm{~cm}^{-1}$, which suggests that the coordination of ICy. ${ }^{(p-t o l)} \mathrm{NCN}$ takes place through the NCN moiety. These observed frequencies are in agreement with reported values. ${ }^{5,25}$

Coordination of CO on the Pt NPs was also studied by solidstate NMR. The ${ }^{13} \mathrm{C}$ CP-MAS NMR spectrum obtained for

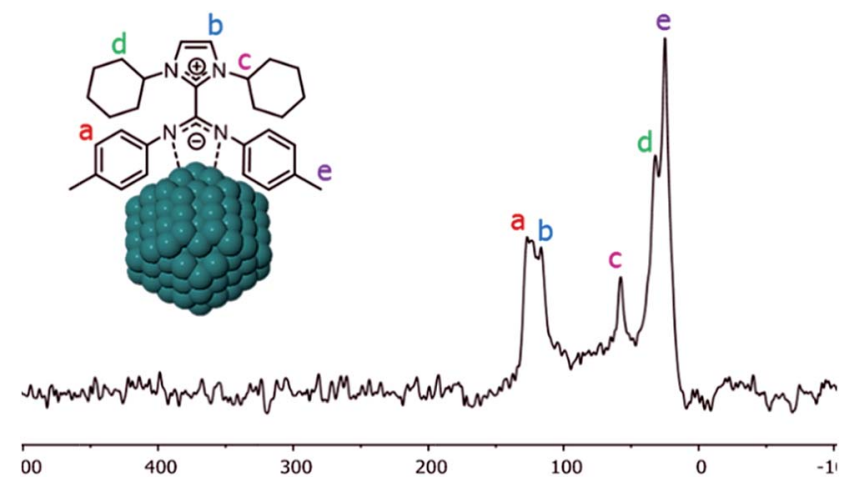

Fig. $4{ }^{13} \mathrm{C}$ CP-MAS NMR spectrum of Pt/ICy. ${ }^{(p-\text { tol })} \mathrm{NCN}_{0.5} \mathrm{NPS}$.

$\mathrm{Pt} / \mathrm{ICy} \cdot{ }^{(p-\text { tol })} \mathrm{NCN}_{0.5}$ before exposition to ${ }^{13} \mathrm{CO}$ displays most of the characteristic signals of the ICy. ${ }^{(p-\text { tol })} \mathrm{NCN}$ ligand (Fig. 4). The group of peaks at $125 \mathrm{ppm}$ (a) corresponds to the aromatic ring of the $p$-tolyl moiety and the signal at $116 \mathrm{ppm}$ (b) belongs to the aromatic imidazolium backbone. The distinctive peak at $58 \mathrm{ppm}$ (c) is attributed to the methine group next to the nitrogen atom. The cyclohexyl methylene resonances are observed between $32 \mathrm{ppm}$ and $25 \mathrm{ppm}$ (d) overlapping with the $p$-tolyl methyl group resonance at $25 \mathrm{ppm}(\mathrm{e})$. As was previously observed for Ru/ICy ${ }^{(p-t o l)} \mathrm{NCN}$, the signals for the $\mathrm{C}_{\text {ipso }}$ of the $p$ tolyl group and the imidazolium and carbodiimide quaternary NCN atoms are not clearly observable in the ${ }^{13} \mathrm{C}$ spectrum (usually in the 130-150 ppm range; see ESI, Fig. S33†) due to a line broadening caused by the coordination of ICy $\cdot{ }^{(p-t o l)} \mathrm{NCN}$ at the metal surface. ${ }^{4}$

When the Pt/ICy. ${ }^{(p-\text { tol })} \mathrm{NCN}_{0.5}$ NPs $(1.9 \mathrm{~nm})$ were exposed to 1 bar of ${ }^{13} \mathrm{CO}$ during $20 \mathrm{~h}$ at r.t., the ${ }^{13} \mathrm{C}$ MAS NMR spectrum [Fig. 5(c)] showed a very broad peak centered at $c a .360 \mathrm{ppm}$ which corresponds to coordinated CO. This broad and high frequency resonance can be assigned to a Knight-shifted ${ }^{13} \mathrm{CO}$ signal. In the ${ }^{13} \mathrm{C}$ MAS spectra of $\mathrm{Pt} / \mathrm{ICy} \cdot{ }^{(p-t o l)} \mathrm{NCN}_{0.2}(2.1 \mathrm{~nm})$

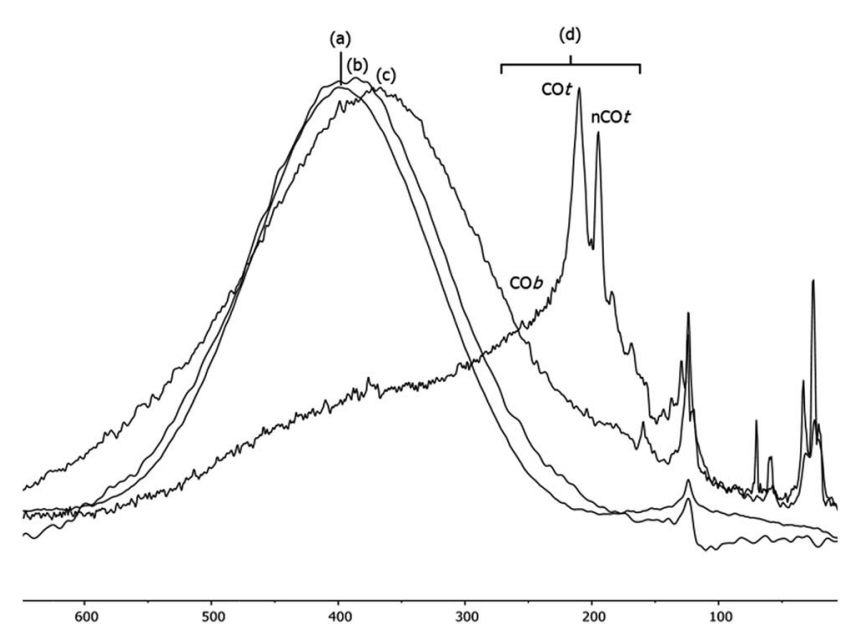

Fig. $5{ }^{13} \mathrm{C}$ MAS NMR spectrum of (a) Pt/ICy. ${ }^{(p-t o l)} \mathrm{NCN}_{0.1}(2.3 \mathrm{~nm}),(b)$ $\mathrm{Pt} / \mathrm{ICy} \cdot{ }^{(p-\text { tol })} \mathrm{NCN}_{0.2}(2.1 \mathrm{~nm}),(\mathrm{c}) \mathrm{Pt} / \mathrm{ICy} \cdot{ }^{(p-\text { tol })} \mathrm{NCN}_{0.5}(1.9 \mathrm{~nm})$ and $(\mathrm{d})$ $\mathrm{Pt} / \mathrm{CO} / \mathrm{ICy} \cdot{ }^{(p-\text { tol })} \mathrm{NCN}_{0.2}(1.2 \mathrm{~nm})$ after exposure to ${ }^{13} \mathrm{CO}(1 \mathrm{bar}, 20 \mathrm{~h}$, at r.t.). 
1) $\mathrm{Pt}_{2}(\mathrm{dba})_{3} \frac{\mathrm{THF}}{\mathrm{CO}(1 \mathrm{bar})} \mathrm{Pt}_{x}(\mathrm{CO})_{y}(\mathrm{THF})_{z}$

2) $\mathrm{Pt}_{x}(\mathrm{CO})_{y}(\mathrm{THF})_{z}+0.2 \mathrm{ICy} \cdot(\mathrm{Ar}) \mathrm{NCN} \stackrel{\mathrm{THF}}{\longrightarrow} \mathrm{Pt} / \mathrm{CO} / \mathrm{ICy} \cdot(\mathrm{Ar}) \mathrm{NCN}_{0.2}$

$$
(\mathrm{Ar}=\mathrm{Ph}, p-\mathrm{Tol})
$$

Scheme 3 Synthesis of Pt/CO/ICy. ${ }^{(p-\text { tol })} \mathrm{NCN}_{0.2}$ NPs.

and Pt/ICy $\cdot\left({ }^{(p-t o l)} \mathrm{NCN}_{0.1}(2.3 \mathrm{~nm})\right.$ after reaction with ${ }^{13} \mathrm{CO}$ we also observed the broad peak of CO at 390 and $400 \mathrm{ppm}$ respectively [Fig. 5(a) and (b)]. Thus, when the size of the NPs decreases, the CO signal is displaced to lower frequency. Because of the fast relaxation associated with the presence of surface electrons (paramagnetic effect), the efficiency of the magnetization transfer in the $\mathrm{CP}$ experiments is dramatically reduced and no signal for the coordinated $\mathrm{CO}$ could be observed in the ${ }^{13} \mathrm{C}$ CPMAS spectra (see ESI, bottom of Fig. S28, S30 and S32†). As we observed an evident relationship between the size and the magnitude of the Knight shift on the CO band, we decided to synthesize very small Pt/ICy. ${ }^{(p-t o l)} \mathrm{NCN} N P s$ with the intention to suppress the Knight shift completely. Pt NPs of $c a .1 .2(0.3) \mathrm{nm}$ (see ESI, Fig. S8 $\dagger$ ) were prepared using a well-known two-step procedure. ${ }^{7,23 a} \mathrm{Pt}_{2}(\mathrm{DBA})_{3}$ was decomposed under 1 bar of $\mathrm{CO}$ in THF, forming the colloid $\mathrm{Pt}_{x}(\mathrm{CO})_{y}(\mathrm{THF})_{z}$, and after washing this colloid with pentane, 0.2 equiv. of ICy ${ }^{(p \text {-tol) }} \mathrm{NCN}$ were added to obtain Pt/CO-ICy $\cdot{ }^{(p-\text { tol })} \mathrm{NCN}_{0.2}$ NPs (Scheme 3). The ${ }^{13} \mathrm{C}$ MAS spectrum of $\mathrm{Pt} / \mathrm{CO} / \mathrm{ICy} \cdot{ }^{(p-\text { tol })} \mathrm{NCN}_{0.2}$ [Fig. 5(d)] after reaction with ${ }^{13} \mathrm{CO}$ showed a broad peak at $230 \mathrm{ppm}$ due to bridging $\mathrm{CO}(\mathrm{COb})$ and two sharp peaks at $210 \mathrm{ppm}$ and $194 \mathrm{ppm}$ which correspond to terminal (COt) and multi-terminal CO (nCOt), respectively. These ones are the values expected for bridging and terminal CO in Pt NPs., ${ }^{8,918 b}$ However, we still observe a remaining broad Knight-shifted $\mathrm{CO}$ resonance at $350 \mathrm{ppm}$ due to the $\mathrm{CO}$ coordinated on the larger NPs. ${ }^{13} \mathrm{C}$ Knight-shifted resonances have already been observed in Pt NPs, ${ }^{7-9,26}$ but this is the first case which reports a direct dependence of the size of Pt NPs with the degree of the Knight shift observed, perceiving a displacement of the $\mathrm{CO}$ band as the nanoparticle size decreases $(2.3 \mathrm{~nm}-2.1 \mathrm{~nm}-1.9 \mathrm{~nm})$, and at $1.2 \mathrm{~nm}$ the Knight shift is almost suppressed (Fig. 5).

To understand the state and coordination mode of these amidinate ligands, we used the labelled adduct 1,3-dicyclohexylimidazolium-2-di-phenylcarbodiimide (ICy. $\left({ }^{(\mathrm{Ph})} \mathrm{NC}^{15} \mathrm{~N}\right.$ ) and studied its coordination on the NP metal surface by ${ }^{15} \mathrm{~N}$ MAS NMR spectroscopy. ICy ${ }^{(\mathrm{Ph})} \mathrm{NC}^{15} \mathrm{~N}$ was fully characterized by NMR (liquid and solid state) and DFT calculations (see ESI, $\dagger$ Section S1). Employing the aforementioned synthetic method, $\mathrm{Pt} / \mathrm{ICy} \cdot{ }^{(\mathrm{Ph})} \mathrm{NC}^{15} \mathrm{~N}_{0.5}$ NPs with an average size of $1.9(0.2) \mathrm{nm}$ (see ESI, Fig. S9 $\dagger$ ) were prepared (Scheme 1). These NPs were studied by ${ }^{15} \mathrm{~N}$ MAS NMR but we could not observe any detectable signal in ${ }^{15} \mathrm{~N}$ Hahn-echo NMR [see ESI, Fig. S36(a)†] not even in ${ }^{15} \mathrm{~N}$ $\mathrm{CP} /$ Hahn-echo MAS NMR [see ESI, Fig. S36(b)†], which are usually employed to detect broad NMR signals. The lack of signals is possibly due to the Knight shift as discussed above.

To suppress the Knight shift we synthesized Pt NPs of $c a$. $1.2 \mathrm{~nm}$ with labelled ICy. ${ }^{(\mathrm{Ph})} \mathrm{NC}^{15} \mathrm{~N}, \mathrm{Pt} / \mathrm{CO} / \mathrm{ICy} \cdot{ }^{(\mathrm{Ph})} \mathrm{NC}^{15} \mathrm{~N}_{0.2}$ (see ESI, Fig. S10†). The ${ }^{15} \mathrm{~N}$ CP/Hahn-echo MAS NMR spectrum displays two sharp signals at 120 and 260 ppm [Fig. 6(a)]. The sharpness of the signals points to a non-coordinated nitrogen compound, as the signals of coordinated ligands are usually broad. The intense peak at $120 \mathrm{ppm}$ is reminiscent of a protonated nitrogen ligand, therefore we prepared the singlyprotonated phenyl betaine adduct as its tetraphenylborate salt $\left[\mathrm{ICy} \cdot{ }^{(\mathrm{Ph})} \mathrm{NC}^{15} \mathrm{NH}\right]^{+}\left[\mathrm{BPh}_{4}\right]^{-}$. In contrast with the strongly basic ligand $\mathrm{Me}_{2} \mathrm{IiPr} \cdot{ }^{(\mathrm{iPr})} \mathrm{NCN}$ reported by Kuhn, ${ }^{27}$ aryl imidazoliumamidinate ICy ${ }^{(\mathrm{Ar})} \mathrm{NCN}($ e.g. $\mathrm{Ar}=\mathrm{Tol})$ does not react with water to a significant extent, but they are immediately protonated by acetic acid (HOAc). [ $\left.\mathrm{ICy} \cdot{ }^{\left(\mathrm{Ph}^{2}\right.} \mathrm{NC}^{15} \mathrm{NH}\right]^{+}\left[\mathrm{BPh}_{4}\right]^{-}$was obtained reacting ICy. ${ }^{(\mathrm{Ph})} \mathrm{NC}^{15} \mathrm{~N}$ with HOAc in the presence of $\mathrm{NaBPh}_{4}$. Indeed the solid-state ${ }^{15} \mathrm{~N} \mathrm{CP} / \mathrm{Hahn}$-echo MAS spectrum of this compound exhibits two signals at 116 and $266 \mathrm{ppm}$, attributed to the protonated and non-protonated $\mathrm{N}$ atoms, respectively. The former is $c a$. four-fold as intense as the latter, because the $\mathrm{CP}$ effect is much more intense in the protonated nitrogen due to the presence of the strong $\mathrm{N}-\mathrm{H}$ dipolar coupling [Fig. 6(b)]. Solution NMR spectra in $\mathrm{CD}_{2} \mathrm{Cl}_{2}$ (see ESI, $\uparrow$ Section S1) indicate that the cation exists as a $2: 1$ mixture of two isomers obtained by protonation of either one of the two N-atoms. DFT calculations confirm the experimental shifts and corroborate that the two $E / Z$ isomers of $\left[\mathrm{ICy} \cdot{ }^{(\mathrm{Ph})} \mathrm{NC}^{15} \mathrm{NH}\right]^{+}\left[\mathrm{BPh}_{4}\right]^{-}$can coexist as evidenced by their relative energy difference of $1.1 \mathrm{kcal} \mathrm{mol}^{-1}$. In the same way as for non-protonated ligands, the $E / Z$ isomers are more stable than the $Z / Z$ isomer by $-3.4 \mathrm{kcal} \mathrm{mol}^{-1}$ and $-2.3 \mathrm{kcal} \mathrm{mol}^{-1}$ (see ESI, Fig. S59†). Thus, the peaks at 120 and $260 \mathrm{ppm}$ in the ${ }^{15} \mathrm{~N} \mathrm{CP} / \mathrm{Hahn}$-echo MAS NMR spectrum of Pt/ $\mathrm{CO} / \mathrm{ICy} \cdot{ }^{(\mathrm{Ph})} \mathrm{NC}^{15} \mathrm{~N}_{0.2}$ correspond to a minor part of the ligand that has been protonated during the synthesis and the signal of which is strongly enhanced thanks to the ${ }^{15} \mathrm{~N}$ CP-MAS experiment. However, we were not able to detect ${ }^{15} \mathrm{~N}$ resonances of coordinated ICy. ${ }^{(\mathrm{Ph})} \mathrm{NC}^{15} \mathrm{~N}$ in ${ }^{15} \mathrm{~N}$ Hahn-echo MAS NMR, most likely because of the deleterious effect of the NP surface electrons (see ESI, Fig. S38†).

$\mathrm{X}$-ray photoelectron spectroscopy (XPS) is an ideal technique to measure the elemental composition and chemical state of surface catalysts. Recently, this technique has been described as a useful tool to investigate the binding mode of NHC ligands on

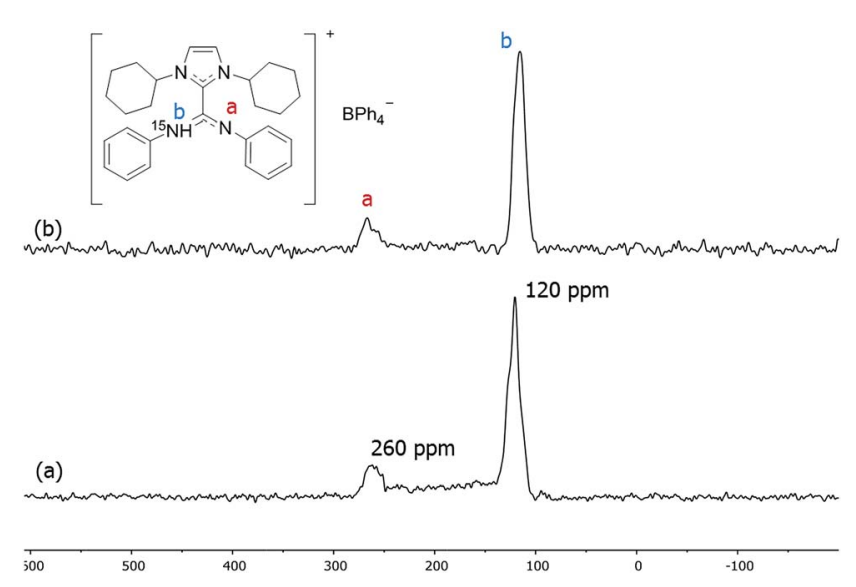

Fig. $6{ }^{15} \mathrm{~N} \mathrm{CP} / \mathrm{Hahn}$-echo MAS of (a) Pt/CO/ICy. ${ }^{(\mathrm{Ph})} \mathrm{NC}^{15} \mathrm{~N}_{0.2}$ and (b) $\left[\mathrm{H} \cdot \mathrm{ICy} \cdot{ }^{(\mathrm{Ph})} \mathrm{NC} \mathrm{C}^{15} \mathrm{~N}\right]^{+} \cdot\left[\mathrm{BPh}_{4}\right]^{-}$. 
a metal surface. ${ }^{28}$ Thus, we applied XPS to study the coordination of the imidazolium-amidinate ligands in our Pt NPs. The N 1s signals of $\mathrm{ICy}^{(p-\text { tol })} \mathrm{NCN}$ present binding energies (BE) of 401.3 and $397.4 \mathrm{eV}$ [Fig. 7(a), blue]. The highest BE peak at $401.3 \mathrm{eV}$ can be assigned to the tightly bound electrons of the nitrogen atoms of the imidazolium fragment. The second peak at $397.4 \mathrm{eV}$ derives from the $\mathrm{N}$ atoms of the amidinate group, which bear partial negative charges. ${ }^{29}$ The coordination of ICy. ${ }^{(p-\text { tol })} \mathrm{NCN}$ through the latter $\mathrm{N}$-atoms to the platinum surface involves a loss of electron density, which increases the binding energy (400.1 eV) compared to the $\mathrm{N}$-atoms of free ICy ${ }^{(p-t o l)} \mathrm{NCN}(397.4 \mathrm{eV})$. This leads to the overlap of the peaks of the two fragments, as can be seen in Fig. 7(a) (red). This signal is the result of convolutions of peaks corresponding to imidazolium and amidinate $\mathrm{N}$ atoms, coordinated or not. In order to improve our understanding of these binding energies, we theoretically compared the natural charges of the $\mathrm{N}$ atoms of the ICy. ${ }^{(\mathrm{Ph})} \mathrm{NCN}$ ligand, free and coordinated in $\mu^{2}-\kappa^{1} \mathrm{~N}, \kappa^{1} \mathrm{~N}^{\prime}$ mode to a model Ru carbonyl cluster (see ESI, Fig. S60 $\dagger$ ). Interestingly, no change is observed in the natural charges of the $\mathrm{N}$ atoms of the imidazolium fragment by coordination of the ligand on the cluster surface. However, the anionic character of the $\mathrm{N}$ atoms of the amidinate moiety is partially reduced, as a result of the balance between $\sigma$-donation and $\pi$-backdonation. Thus, the coordination of the ligand induces the decrease of the charge difference between the $\mathrm{N}$ atoms of both moieties leading to overlap of the peaks of the two fragments as observed in Fig. 7(a) (red). This result suggests that the coordination of the ligand to the nanoparticle is through the $\mathrm{N}$ atoms of the amidinate moiety. We deconvoluted the $\mathrm{N} 1 \mathrm{~s}$ signals of $\mathrm{Pt} / \mathrm{ICy} \cdot{ }^{(p-\text { tol })} \mathrm{NCN}_{0.2}$ at $399.9 \mathrm{eV}$ in three contributions with different binding energies, at 401.1, 399.7 and 398.2, corresponding to $\delta^{-}$, neutral and $\delta^{+} \mathrm{N}$ atoms, respectively [Fig. 7(c),

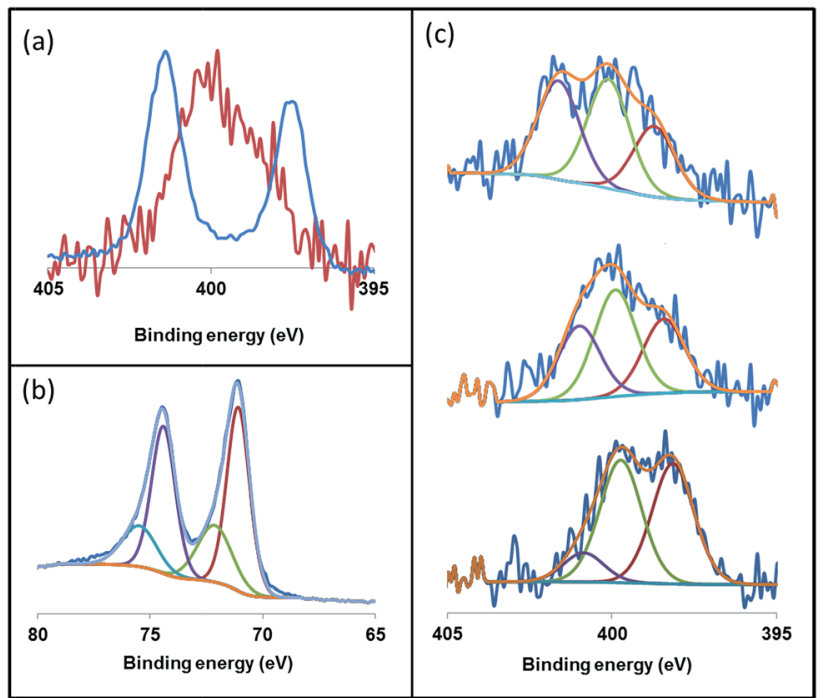

Fig. 7 X-ray photoelectron spectroscopy (XPS) of (a) the $N$ 1s signals of ICy. ${ }^{\left({ }^{-t o l}\right)} \mathrm{NCN}$ (blue) and Pt/ICy. ${ }^{(p-\text { tol })} \mathrm{NCN}_{0.2}$ (red), (b) the Pt $4 f_{5 / 2}$ and $4 \mathrm{f}_{7 / 2}$ signals of $\mathrm{Pt} / \mathrm{ICy} \cdot{ }^{(p-t o l)} \mathrm{NCN}_{0.2}$ and $(\mathrm{c})$ the $\mathrm{N}$ 1s signals of $\mathrm{Pt} /$ $\mathrm{ICy} \cdot{ }^{\left(p-\mathrm{ClC}_{6} \mathrm{H}_{4}\right)} \mathrm{NCN}_{0.2}$ (top), $\mathrm{Pt} / \mathrm{ICy} \cdot{ }^{(p-\text { tol) }} \mathrm{NCN}_{0.2}$ (center) and Pt/ ICy. (p-anisyl) $\mathrm{NCN}_{0.2}$ (bottom). center]. When the electron-withdrawing ligand ICy. $\left(p-\mathrm{ClC}_{6} \mathrm{H}_{4}\right)$ NCN is used as stabilizer, the contribution of the peak at 401.1 $\left(\mathrm{N}^{\delta+}\right)$ intensifies, generating an increase of the average BE of the $\mathrm{N}$ 1s signal to $400.8 \mathrm{eV}$ [Fig. 7(c), top]. On the other hand, the $\mathrm{N}(1 \mathrm{~s})$ signals of $\mathrm{Pt} / \mathrm{ICy} \cdot{ }^{(p-a n i s y l)} \mathrm{NCN}_{0.2}$ containing the electron donor OMe substituent, display the opposite behavior, intensifying the peak at $398.2\left(\mathrm{~N}^{\delta-}\right)$ and decreasing the global BE to $398.7 \mathrm{eV}$ [Fig. 7 (c), bottom]. The binding energy of $\mathrm{Pt} 4 \mathrm{f}_{7 / 2}$ in the XPS spectra of $\mathrm{Pt} / \mathrm{ICy} \cdot{ }^{(p \text {-tol })} \mathrm{NCN}_{0.2} \mathrm{NPs}$ is $71.1 \mathrm{eV}$. The main contribution is located at $71.0 \mathrm{eV}$, which is characteristic of $\mathrm{Pt}(0),{ }^{30}$ and an additional contribution at $72.7 \mathrm{eV}$ is attributed to the surface platinum atoms linked to the nitrogen atoms of ICy. ${ }^{(p \text {-tol })} \mathrm{NCN}(\operatorname{Pt}(\delta+))[$ Fig. $7(\mathrm{~b})] .^{31}$

\section{Coordination of imidazolium-amidinates to metal surfaces}

Amidinates have a rich coordination chemistry ${ }^{32}$ as they can coordinate to a single metal center either in terminal $\left(\kappa^{1}\right)$, chelating $\left(\kappa^{2}\right)$ modes, and, less often they can even bind in $\eta^{3}$ mode, like an allyl group. The amidinate can also bridge two metal centers, i.e., in $\mu_{2}-\kappa^{1} \mathrm{~N}, \kappa^{1} \mathrm{~N}^{\prime}$ mode. On a metal surface one $\mathrm{N}$-atom can bridge more than two metal atoms and thus a variety of coordination modes results. As the measurements on Pt NPs gave not satisfactory evidence for the bonding mode in ${ }^{15} \mathrm{~N}$ NMR spectroscopy we turned to different metals for ${ }^{15} \mathrm{~N}$ NMR spectral data. As ruthenium presents insignificant or no Knight shift, we synthesized $\mathrm{Ru} / \mathrm{ICy} \cdot{ }^{(\mathrm{Ph})} \mathrm{NCN}$ NPs as reported before $^{4}$ stabilized with $0.1,0.2,0.5$ and 1 equiv. of the ${ }^{15} \mathrm{~N}$ labelled ligand and studied the coordination of the ligand by solid state ${ }^{15} \mathrm{~N}$ MAS NMR. The resulting Ru/ICy. ${ }^{(\mathrm{Ph})} \mathrm{NC}^{15} \mathrm{~N}$ NPs have sizes between 1.0 and $1.3 \mathrm{~nm}$, they are very well dispersed and show a narrow size distribution (see ESI, Fig. S11-S14†). As for Pt NPs, we perceived a correlation between the size and the amount of ligand used during the synthesis; the size increases when less ligand is used.

In the ${ }^{15} \mathrm{~N} \mathrm{CP} / \mathrm{Hahn}$-echo MAS NMR spectra of $\mathrm{Ru} /$ ICy. ${ }^{(P h)} \mathrm{NC}^{15} \mathrm{~N}$ NPs (see ESI, Fig. S43†) we can see clearly the peak around $120 \mathrm{ppm}$ corresponding to the protonated amidinate ligand, as was already observed for Pt/CO/ICy ${ }^{(\mathrm{Ph})} \mathrm{NC}^{15} \mathrm{~N}_{0.2}$. Furthermore, a new broad featureless signal is observed underneath the ${ }^{15} \mathrm{~N}$ resonance of the protonated imidazoliumamidinate ligand. Note that for Ru NPs stabilized with 1 equiv. [see ESI, Fig. S43(a)†], we also observed a sharp peak at $212 \mathrm{ppm}$ assigned to the excess of free ligand. ${ }^{15} \mathrm{~N}$ Hahn-echo MAS NMR spectra (see ESI, Fig. S45, S48, S54 and S57 $\dagger$ ) allowed the amplification of this new broad ${ }^{15} \mathrm{~N}$ resonance relative to the signal of the protonated free ligand. Unfortunately, the broadness and the poor signal to noise ratio of these experiments still preclude a clear characterization of the ${ }^{15} \mathrm{~N}$ signals. In order to increase the sensitivity of the ${ }^{15} \mathrm{~N}$ MAS experiments, we used the Carr-Purcell-Meiboom-Gill pulse sequence (CPMG). ${ }^{33}$ It works well for NMR resonances that have long spin-state lifetimes but significant inhomogeneous broadening. Fig. 8 displays the ${ }^{15} \mathrm{~N}$ CPMG MAS NMR spectra of Ru/ICy. ${ }^{(\mathrm{Ph})} \mathrm{NC}^{15} \mathrm{~N}$ NPs stabilized with the different amounts of ICy ${ }^{(P h)} \mathrm{NC}^{15} \mathrm{~N}$. With this series of experiments and DFT calculations on the chemical shifts we could establish the different states and coordination modes of 
the amidinate at the Ru surface. The broad peak centered at $c a$. $250( \pm 100) \mathrm{ppm}$ corresponds to coordinated ICy. ${ }^{(\mathrm{Ph})} \mathrm{NC}^{15} \mathrm{~N}$ which can coordinate in different ways. Following a computational strategy successfully used for computing ${ }^{1} \mathrm{H}$ and ${ }^{13} \mathrm{C}$ chemical shifts, a $\left[\mathrm{Ru}_{6}\right]$ carbonyl cluster was first used as a model for Ru NPs as larger systems cannot be conveniently handled. ${ }^{34}$ The chemical shifts were calculated by DFT studies and compared with the observed ones (see ESI, Fig. S61†). When ICy $\cdot{ }^{(\mathrm{Ph})} \mathrm{NC}^{15} \mathrm{~N}$ bridges two adjacent $\mathrm{Ru}$ atoms, the estimated deltas are 221 and 205 ppm [see ESI, Fig. S61(a)†] ( $\kappa^{2}$ coordination to one metal is not a stable configuration, vide infra). For $\kappa^{1}$ coordination the calculated chemical shifts are $244 \mathrm{ppm}$ for the non-coordinated nitrogen and $118 \mathrm{ppm}$ for the bound one [see ESI, Fig. S61(b)†]. These values change to 262 and 134 ppm if there is $\pi$-stacking between the phenyl groups and the ruthenium surface [see ESI, Fig. S61(c) $\dagger$ ]. In view of the broadness of the resonances centered at $c a .250 \mathrm{ppm}\left(\Delta \nu_{1 / 2}=100-300\right.$ $\mathrm{ppm})$, the ${ }^{15} \mathrm{~N}$ NMR spectrum suggests that all three coordination modes are present.

Lastly, the broad peak observed between 315 and $380 \mathrm{ppm}$ in the ${ }^{15} \mathrm{~N}$ CPMG MAS NMR spectra of $\mathrm{Ru} / \mathrm{ICy} \cdot{ }^{(\mathrm{Ph})} \mathrm{NC}^{15} \mathrm{~N}$ NPs (Fig. 8) is attributed to a species resulting from an insertion reaction of amidinate and carbon monoxide on the surface. This conclusion was corroborated by pressurization of $\mathrm{Ru} /$ ICy $\cdot{ }^{(\mathrm{Ph})} \mathrm{NC}^{15} \mathrm{~N}_{0.2}$ NPs with ${ }^{13} \mathrm{CO}(1$ bar, r.t., 20 h), which led to a significant increase of these resonances (Fig. 9). ${ }^{35}$ Unfortunately, the peak corresponding to $\mathrm{CO}^{\text {ins }}$, expected at $219 \mathrm{ppm}$ in ${ }^{13} \mathrm{C}$ MAS NMR, cannot be observed due to overlap with the broad peak of COb centered at $230 \mathrm{ppm}$ (see ESI, Fig. S51†). The calculated ${ }^{15} \mathrm{~N}$ shifts of monocoordinated ICy. ${ }^{(\mathrm{Ph})} \mathrm{NC}^{15} \mathrm{~N}$ after insertion of $\mathrm{CO}$ are $151 \mathrm{ppm}$ for the migrated $\mathrm{N}$-atom and 308 ppm for the non-coordinated N-atom (Fig. 9). After a careful analysis of NPA charges on this cluster model, we conclude that this significant unshielding of the latter is due to

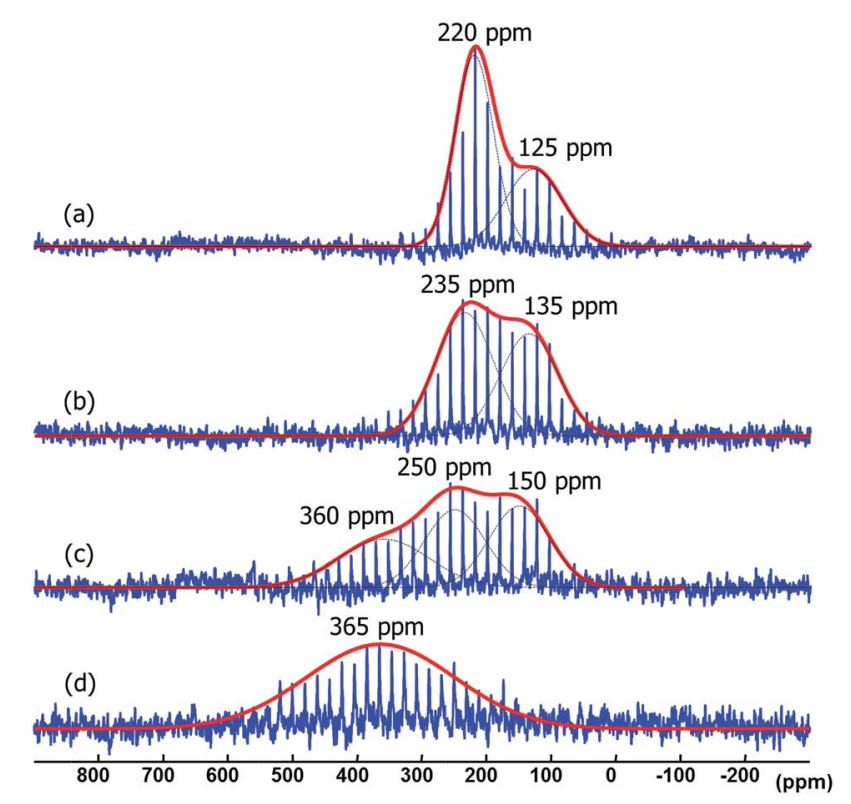

Fig. $8{ }^{15} \mathrm{~N}$ CPMG MAS NMR of Ru/ICy. ${ }^{\left({ }^{(h)}\right)} \mathrm{NC}^{15} \mathrm{~N}$ stabilized with (a) 1 equiv., (b) 0.5 equiv., (c) 0.2 equiv. and (d) 0.1 equiv. a delocalization of the negative charge on the $\mathrm{CO}-\mathrm{Ru}$ fragment and the localization of the $\pi$ bond between $\mathrm{C}$ and this ${ }^{15} \mathrm{~N}$-atom (see ESI, Fig. S62 and S63†). A charge analysis on its $\mathrm{Ru}_{55} \mathrm{NP}$ counterpart leads to the same conclusion (see ESI, Fig. S64†). This $308 \mathrm{ppm}$ value is in the range of ${ }^{15} \mathrm{~N}$ chemical shifts observed for imines. ${ }^{36}$

Subsequently, the energetics of $\mathrm{ICy} \cdot{ }^{(\mathrm{Ph})} \mathrm{NCN}$ coordination onto the Ru surface was investigated by DFT calculations. The chosen model is a Ru nanoparticle of 55 atoms with a hydride coverage of 1.6 hydrides per ruthenium surface atom, which has a size of $c a .1 \mathrm{~nm}\left(\mathrm{Ru}_{55} \mathrm{H}_{70}\right)$. This model, apart from having a size similar $(\sim 1 \mathrm{~nm})$ to our $\mathrm{Ru} / \mathrm{ICy} \cdot{ }^{(\mathrm{Ph})} \mathrm{NCN}$ NPs, has been already satisfactory employed by some of us $^{11}$ to determine the preferred surface composition of Ru NPs as a function of environmental conditions from an application of the $a b$ initio thermodynamics method, ${ }^{37}$ that provides a connection between the microscopic and macroscopic regimes. In the present case, the DFT calculations showed that the most stable coordination mode is through the two nitrogen atoms of the amidinate as the $Z / Z$ conformer to two adjacent Ru-atoms $\left(\mu_{2}-\kappa^{1} \mathrm{~N}, \kappa^{1} \mathrm{~N}^{\prime}\right)$, with a binding energy of $-47.9 \mathrm{kcal} \mathrm{mol}^{-1}$. The binding of the same conformer through only one $\mathrm{N}$ atom has a stability of $-33.3 \mathrm{kcal}$ $\mathrm{mol}^{-1}$, while that of monocoordination of the $E / Z$ conformer is $-25 \mathrm{kcal} \mathrm{mol}^{-1}$ (Fig. 10). When the ligand was initially bound to a single $\mathrm{Ru}$ atom as bidentate $\left(\kappa^{2} \mathrm{~N}, \mathrm{~N}^{\prime}\right)$, geometry optimization led to a more favorable terminal $\kappa^{1} \mathrm{~N}$ coordination mode, as observed for some recently reported $\mathrm{Cu}$ complexes. ${ }^{5}$ Were the bonding prevailingly polar, such bidentate coordination mode could be favored, as observed for amidinate or carboxylate derivatives of the alkali and rare earth metals. ${ }^{38}$ In summary, the adsorption energy per Ru-N bond of a single amidinate which is not sterically discomforted by its mutual interaction with other ICy. ${ }^{(\mathrm{Ph})} \mathrm{NCN}$ ligands lies between -24 and $-33 \mathrm{kcal} \mathrm{mol}^{-1}$.

It is interesting to note that the interaction between the ICy ${ }^{(\mathrm{Ph})} \mathrm{NCN}$ ligand and the $\mathrm{Ru}_{55}$ nanoparticle does not involve a displacement of the surface hydrides, considering that the loss of four $\mathrm{H}_{2}$ molecules is disfavored by $+20.6 \mathrm{kcal} \mathrm{mol}^{-1}$ (see ESI, Fig. S65 $\dagger$ ). The maximum number of $\mu_{2}-\kappa^{1} \mathrm{~N}, \kappa^{1} \mathrm{~N}^{\prime}$ coordinated ICy $\cdot{ }^{(\mathrm{Ph})} \mathrm{NCN}$ ligands that we can fit on the $\mathrm{Ru}_{55}$ surface is six (see ESI, Fig. S66†), which corresponds with Ru NPs

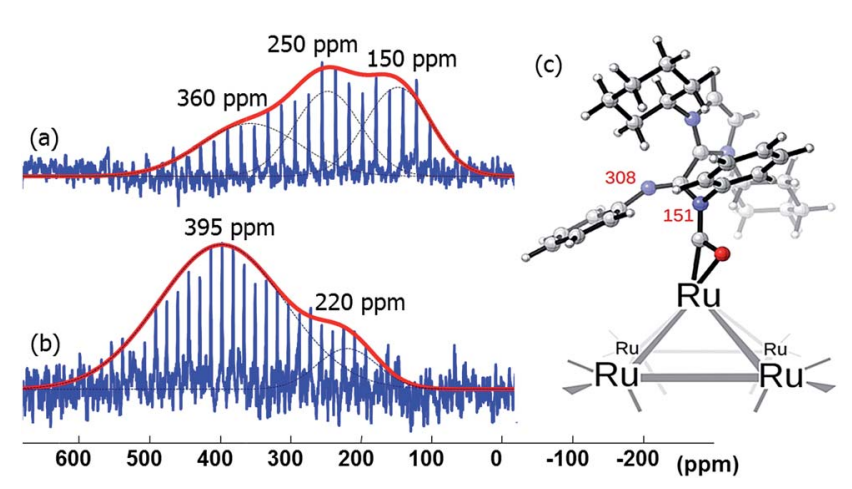

Fig. $9{ }^{15} \mathrm{~N}$ CPMG MAS NMR of Ru/ICy. ${ }^{(\mathrm{Ph})} \mathrm{NC}^{15} \mathrm{~N}_{0.2}$ (a) before and (b) after exposure to ${ }^{13} \mathrm{CO}$ (1 bar, 20 h, at r.t.). (c) Calculated ${ }^{15} \mathrm{~N} N M R$ displacements of $\mathrm{ICy} \cdot{ }^{(\mathrm{Ph})} \mathrm{NCN}$ after $\mathrm{CO}$ insertion on a $\left[\mathrm{Ru}_{6}\right]$ cluster model. 


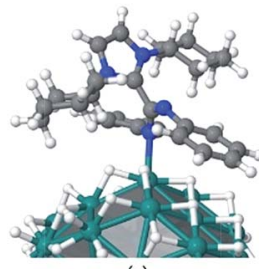

(a)

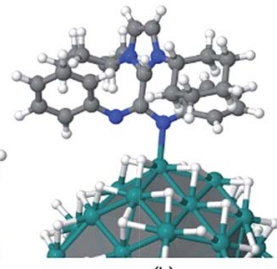

(b)

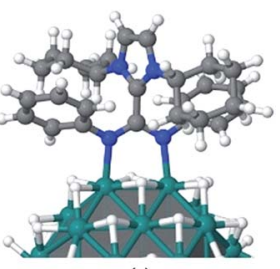

(c)
Fig. 10 Coordination modes of $\mathrm{ICy} \cdot{ }^{(\mathrm{Ph})} \mathrm{NCN}$ at the $\mathrm{Ru}_{55} \mathrm{H}_{70}$ surface (a) $\kappa^{1} \mathrm{~N}$ monocoordinated $Z / E$ conformer $\left(E_{\text {ads }}:-25.0 \mathrm{kcal} \mathrm{mol}^{-1}\right) ;(b) \kappa^{1} \mathrm{~N}$ monocoordinated $Z / Z$ conformer $\left(E_{\text {ads }}:-33.3 \mathrm{kcal} \mathrm{mol}^{-1}\right.$ ); (c) $\mu_{2}-\kappa^{1} \mathrm{~N}$, $\kappa^{1} \mathrm{~N}^{\prime}$ bicoordinated $Z / Z$ conformer $\left(E_{\text {ads }}:-47.9 \mathrm{kcal} \mathrm{mol}^{-1}\right)$.

stabilized with 0.1 equiv. of the ligand. The adsorption strength per betaine is lowered from $-47.9 \mathrm{kcal} \mathrm{mol}^{-1}$ in the case of a single ligand to $-29.1 \mathrm{kcal} \mathrm{mol}^{-1}$ for the maximum number of them (i.e., 6). For $\kappa^{1}$ coordinated amidinates one could fit perhaps a few more ligands on the surface, which is still energetically favorable. Thus, the Ru/ICy ${ }^{(\mathrm{Ph})} \mathrm{NC}^{15} \mathrm{~N}$ NPs stabilized with $0.2,0.5$ and 1 equiv. have a second sphere of non-coordinated ICy $\left({ }^{(\mathrm{Ph})} \mathrm{NC}^{15} \mathrm{~N}\right.$ which is strongly bonded to the first sphere by ionic and $\pi-\pi$ stacking interactions. At least some part of the second sphere is present in the protonated form as indicated by ${ }^{15} \mathrm{~N}$ NMR.

We shall now evaluate the coordination energy of the species resulting from an insertion reaction of $\mathrm{CO}$ into the $\mathrm{Ru}-\mathrm{N}$ bonds, which we shall call $\mathrm{CO}^{\text {ins }}$, responsible for the broad peak observed between 315 and $380 \mathrm{ppm}$ in the ${ }^{15} \mathrm{~N}$ NMR spectrum of carbonylated nanoparticles using the $\left[\mathrm{Ru}_{55}\right]$ cluster model. We initially considered a $\mathrm{Ru}_{55}(\mathrm{CO})_{66}$ cluster, with a coverage corresponding to $1.5 \mathrm{CO}$ per surface $\mathrm{Ru}$ atom, as established in previous ab initio thermodynamics calculations..$^{12}$ The adsorption energies of $\mu_{2}-\kappa^{1} \mathrm{~N}, \kappa^{1} \mathrm{~N}^{\prime}$ bicoordinated ICy. ${ }^{(\mathrm{Ph})} \mathrm{NCN}, \kappa^{1} \mathrm{~N}$ monocoordinated $Z / Z$ conformer and the $\mathrm{CO}^{\text {ins }}$ compound are slightly endothermic by 3-5 $\mathrm{kcal} \mathrm{mol}^{-1}$ whatever the ligand, probably owing to the crowding of carbon monoxides on the surface. This is why we considered the adsorption properties on a $\mathrm{Ru}_{55}(\mathrm{CO})_{59}$ cluster. The adsorption energy of the $\mathrm{CO}^{\text {ins }}$ compound becomes exothermic by $-27.3 \mathrm{kcal} \mathrm{mol}^{-1}$ - a value similar to the Ru-N bond energy - and its grafting mode is similar to what has been obtained on the small $\left[\mathrm{Ru}_{6}\right]$ cluster (see ESI, Fig. S67 $\dagger$ ). Although its adsorption is strongly exothermic, it is significantly less strongly bound than bicoordinated ICy. ${ }^{(\mathrm{Ph})} \mathrm{NCN}$ ligands $\left(\mu_{2}-\kappa^{1} \mathrm{~N}, \kappa^{1} \mathrm{~N}^{\prime}\right.$ and $\left.\kappa^{2} \mathrm{~N}, \mathrm{~N}^{\prime}\right)$ (between -47 $\mathrm{kcal} \mathrm{mol}^{-1}$ and $-76 \mathrm{kcal} \mathrm{mol}^{-1}$ depending on the grafting site, i.e. between -24 and $-38 \mathrm{kcal} \mathrm{mol}^{-1}$ per $\mathrm{Ru}-\mathrm{N}$ bond, close to the values calculated for the $\mathrm{Ru}_{55} \mathrm{H}_{70}$ model). These results suggest that, according to thermodynamics, $\mathrm{CO}$ insertion will more likely occur on the monocoordinated amidinate ligands.

In conclusion, the DFT calculations fully support the ${ }^{15} \mathrm{NMR}$ measurements in that the Ru NPs are covered with $\mu_{2}-\kappa^{1} \mathrm{~N}, \kappa^{1} \mathrm{~N}^{\prime}$ amidinates, $\kappa^{1}$ coordinated amidinates, and free ligand in part in protonated form. The counter anion of the latter is not known as the synthesis of the MNPs does not involve salts. In the absence of conclusive ${ }^{15} \mathrm{NMR}$ measurements for Pt NPs we propose that the coordination mode is the same as that found for Ru.

\section{Catalytic studies}

To probe the catalytic activity and chemoselectivity of the new NPs we chose Pt/ICy. ${ }^{(p-t o l)} \mathrm{NCN}_{0.2}$ as model system and tested it in the hydrogenation of several substrates containing various functional groups such as olefinic bonds, carbonyl groups, and aromatic rings. In addition, we investigated the influence of $N$ aryl groups with different electronic properties using Pt NPs ligated to functionalized imidazolium-amidinate ligands $\left(\mathrm{Pt} / \mathrm{ICy} \cdot(p\right.$-anisyl $) \mathrm{NCN}_{0.2}$ and $\mathrm{Pt} / \mathrm{ICy} \cdot\left(p\right.$-ClC $\left.{ }_{6} \mathrm{H}_{4}\right) \mathrm{NCN}_{0.2}$; see ESI Fig. S15 and $\mathrm{S} 16 \dagger)$. The catalytic results gave interesting differences in terms of activity depending on the type of stabilizing ligand used. In general, all nanocatalysts hydrogenated olefinic and $\mathrm{C}=\mathrm{O}$ bonds, but, as was expected for Pt NPs, they were not capable of hydrogenating aromatic rings; e.g. the hydrogenation of styrene catalyzed by $\mathrm{Pt} / \mathrm{ICy} \cdot{ }^{(p-\text { tol })} \mathrm{NCN}_{0.2}$, gave selectively ethylbenzene with a maximum turn over frequency (TOF) of $75300 \mathrm{~h}^{-1}$ (Table 1). This high TOF value demonstrates the high catalytic power of this system in hydrogenation of olefinic double bonds. This is peculiar in view of the high coverage with strongly bound imidazolium-amidinate ligands and indicates that these ligands play a favorable role as electron donors.

Interestingly, $1.2 \mathrm{~nm} \mathrm{Pt} / \mathrm{CO} / \mathrm{ICy} \cdot{ }^{(\mathrm{Ph})} \mathrm{NC}^{15} \mathrm{~N}_{0.2} \mathrm{NPs}$ prepared from $\mathrm{Pt}_{2}(\mathrm{DBA})_{3}$ and $\mathrm{CO}$ (Scheme 3) were totally inactive in the hydrogenation of styrene, due to their surface poisoned by CO. Indeed, as expected from previous works ${ }^{7,23 a}$ the IR spectrum of such NPs, recorded immediately after the synthesis, presented two characteristic bands for COt and COb at 2041 and 1859 $\mathrm{cm}^{-1}$, respectively which remained essentially unchanged when these are exposed to CO (see ESI, Fig. S24 $\dagger$ ). This confirmed that the Pt surface of $\mathrm{Pt} / \mathrm{CO} / \mathrm{ICy} \cdot{ }^{(\mathrm{Ph})} \mathrm{NC}^{15} \mathrm{~N}_{0.2} \mathrm{NPs}$ was totally covered with $\mathrm{CO}$ due to their synthesis conditions, thus explaining why these NPs are completely inactive as hydrogenation catalyst.

The catalytic behavior of Pt NPs Pt/ICy. $\cdot{ }^{(p-a n i s y l)} \mathrm{NCN}_{0.2}, \mathrm{Pt} /$ ICy $\cdot\left(p^{\left(-\mathrm{ClC}_{6} \mathrm{H}_{4}\right)} \mathrm{NCN}_{0.2}\right.$ and $\mathrm{Pt} / \mathrm{ICy} \cdot{ }^{(p-t o l)} \mathrm{NCN}_{0.2}$ was studied in the hydrogenation of 4-phenyl-3-buten-2-one, 3-methyl-2-cyclohexenone and 4-nitrobenzaldehyde (Table 2, entries 1-9). All reactions were carried out with Pt NPs synthesized with 0.2 equiv. of the corresponding amidinate ligand as the results changed little for Pt NPs prepared with 0.1 or 0.5 equiv. (Table $\mathrm{S} 2 \dagger)$. In all cases, the olefins were smoothly hydrogenated (in less than $1 \mathrm{~h}$ ), but the carbonyl groups reacted more slowly. After $20 \mathrm{~h}$ of reaction, ketone and aldehyde groups were partially

\begin{tabular}{lllll}
\hline Table 1 & \multicolumn{4}{l}{ Hydrogenation of styrene catalyzed by Pt/ICy. ${ }^{(p-t o l)} \mathrm{NCN}_{0.2}$} \\
\hline Entry & Substrate & Products $^{c}$ & Conv. $^{c}(\%)$ & $\mathrm{TOF}^{(}\left(\mathrm{h}^{-1}\right)$ \\
\hline $2^{a}$
\end{tabular}

${ }^{a}$ Reaction conditions: substrate (32 mmol), Pt NPs $(0.0025 \mathrm{mmol}$ of Pt assuming $77.3 \%$ of Pt from TGA analysis), THF ( $3 \mathrm{~mL}$ ), $1 \mathrm{~h}, T=333 \mathrm{~K}$, $P=5$ bar. ${ }^{b}$ Reaction conditions: substrate $(320 \mathrm{mmol})$, Pt NPs $(0.0025$ mmol of Pt assuming $77.3 \%$ of Pt from TGA analysis $)$, THF $(10 \mathrm{~mL})$, $10 \mathrm{~min}, T=333 \mathrm{~K}, P=5$ bar. ${ }^{c}$ Conversions and products identities were determined by ${ }^{1} \mathrm{H}$ NMR (average of two runs). 
Table 2 Hydrogenation reactions catalyzed by Pt/ICy. ${ }^{(p-a n i s y l)} \mathrm{NCN}_{0.2}, \mathrm{Pt} / \mathrm{ICy} \cdot{ }^{(p-t o l)} \mathrm{NCN}_{0.2}$ and Pt/ICy. ${ }^{\left(p-\mathrm{ClC}_{6} \mathrm{H}_{4}\right)} \mathrm{NCN}_{0.2}$

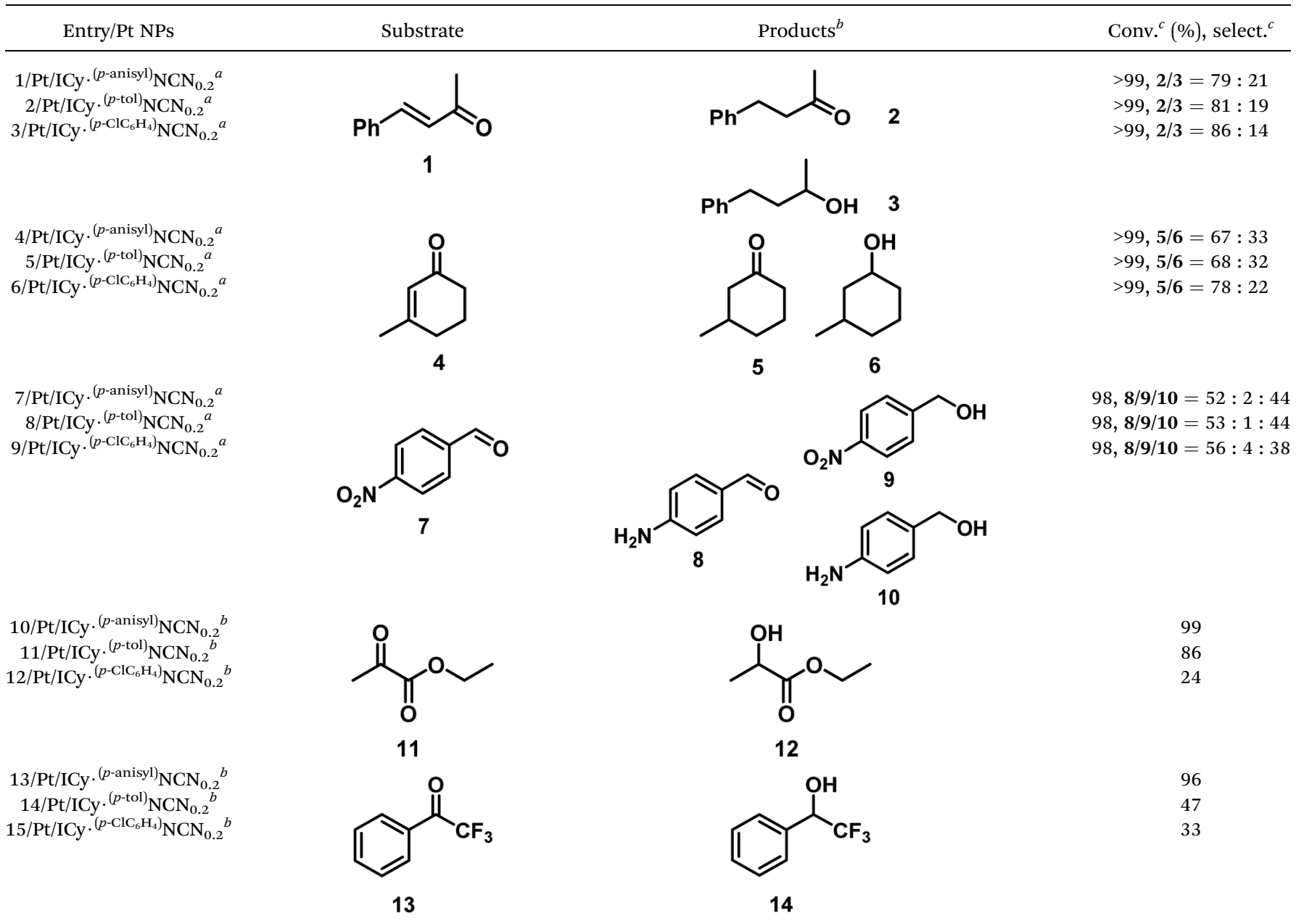

${ }^{a}$ Reaction conditions: substrate $(0.5 \mathrm{mmol})$, Pt NPs $(0.0025 \mathrm{mmol}$ of Pt assuming $77.3 \%$ of Pt from TGA analysis $)$, THF (0.75 mL), $20 \mathrm{~h}, \mathrm{r.t} ., 5 \mathrm{bar}$.

${ }^{b}$ Reaction conditions: substrate (0.5 mmol), Pt NPs ( $0.0025 \mathrm{mmol}$ of Pt assuming $77.3 \%$ of Pt from TGA analysis), THF (0.75 mL), 3 h, r.t., 5 bar.

${ }^{c}$ Conversions, selectivities and products identities were determined by ${ }^{1} \mathrm{H}$ NMR (average of two runs).

hydrogenated in different grades depending on the $N$-aryl group of the ligand. We observed a slight increase in activity with the electron-donor strength of these substituents. Thus, the NPs stabilized with the strongest donor ligand, Pt/ICy ${ }^{(p \text {-anisyl })} \mathrm{NCN}_{0.2}$, were the most active systems in the hydrogenation of the carbonyl group. This trend was more pronounced for ethyl pyruvate (Table 2, entries 10-12). Significant differences of reactivity between the three nanosystems were observed in the hydrogenation of this substrate. This ligand effect was confirmed in the hydrogenation of 2,2,2-trifluoroacetophenone (Table 2, entries 13-15), for which also the Pt NPs ligated by the stronger donor ligand ICy. ${ }^{(p-a n i s y l)}$ NCN provided the most active nanocatalyst for this reaction. We conclude that more electron-rich Pt NPs yield faster catalysts, but as yet we cannot speculate on the mechanism.

\section{Conclusions}

We have successfully ligated zwitterionic amidinates to Pt NPs which leads to the peculiar property that the charges of the anions need no compensation by cationic metal ions as in clusters that contain thiolates on the surface for instance. Usually N-based ligands are weakly binding ligands to MNPs, but unexpectedly amidinates bind strongly to the Pt surface atoms. We have shown that ${ }^{15} \mathrm{~N}$ NMR spectroscopy can be used for the study of the adsorption mode of the nitrogen ligand to the surface with the use of ${ }^{15} \mathrm{~N}$ enriched ligands. The disturbing Knight shifts on the chemical shifts of the surface bound nuclei could be largely suppressed when small Pt NPs were used. Amidinates may well find broader application in MNP and metal nanocluster (MNC) synthesis and catalysis. Even more so because subtle electronic modification of the $N$-aryl groups of the amidinates has an effect on the catalytic performance of the Pt NPs.

\section{Acknowledgements}

This work was supported by CNRS, UPS-Toulouse, INSA, and IDEX/Chaires d'Attractivité de l'Université Fédérale Toulouse 
Midi-Pyrénées, and the Government of Spain (MINECO)/FEDER funds of the EU (project CTQ2015-68978-P). The authors thank V. Collière and L. Datas for TEM facilities (TEMSCAN, UPS), P. Lecante (CEMES, CNRS) for WAXS measurements, C. Bijani for NMR measurements, and P. Jankowski and A. Chapman for useful inspiration on the synthesis of Pt NPs by reduction of $\mathrm{Pt}(\mathrm{NBE})_{3}$. The authors also acknowledge the HPCs CALcul en MIdi-Pyrénées (CALMIP-HYPERION grant P0611) and the Grand Equipement National de Calcul Intensif (GENCI-TGCC, A0010810168).

\section{Notes and references}

1 (a) Clusters and Colloids. From Theory to Applications, ed. G. Schmid, Wiley-VCH, Weinheim, 1994; (b) Nanoparticles. From Theory to Application, ed. G. Schmid, Wiley-VCH, Weinheim, 2004; (c) Nanocatalysis Series Nanoscience and Technology, ed. H. Ulrich and L. Uzi, Springer, Heidelberg, 2007.

2 (a) A. Roucoux, J. Schulz and H. Patin, Chem. Rev., 2002, 102, 3757; (b) Nanoparticles and Catalysis, Wiley-Interscience, New York, 2008; (c) Nanomaterials in Catalysis, ed. P. Serp and K. Philippot, Wiley-VCH, Weinheim2013; (d) A. Roucoux and K. Philippot, in Handbook of Homogeneous Hydrogenations, ed. J. G. de Vries and C. J. Elsevier, Wiley-VCH, Weinheim, 2007, vol. 9, pp. 217-255; (e) E. Bayram, J. C. Linehan, J. L. Fulton, J. A. S. Roberts, N. K. Szymczak, T. D. Smurthwaite, S. Ozkar, M. Balasubramanian and R. G. Finke, J. Am. Chem. Soc., 2011, 133, 18889; (f) A. Balanta, C. Godard and C. Claver, Chem. Soc. Rev., 2011, 40, 4973.

3 (a) K. An and G. A. Somorjai, ChemCatChem, 2012, 4, 1512; (b) D. Gonzalez-Galvez, P. Nolis, K. Philippot, B. Chaudret and P. W. N. M. van Leeuwen, ACS Catal., 2012, 2, 317; (c) L. M. Martinez-Prieto, S. Carenco, C. H. Wu, E. Bonnefille, S. Axnanda, Z. Liu, P. F. Fazzini, K. Philippot, M. Salmeron and B. Chaudret, ACS Catal., 2014, 4, 3160; (d) L. M. Martínez-Prieto, A. Ferry, L. Rakers, C. Richter, P. Lecante, K. Philippot, B. Chaudret and F. Glorius, Chem. Commun., 2016, 52, 4768.

4 L. M. Martinez-Prieto, C. Urbaneja, P. Palma, J. Campora, K. Philippot and B. Chaudret, Chem. Commun., 2015, 51, 4647.

5 A. Marquez, E. Avila, C. Urbaneja, E. Alvarez, P. Palma and J. Campora, Inorg. Chem., 2015, 54, 11007.

6 (a) P. Lara, O. Rivada-Wheelaghan, S. Conejero, R. Poteau, K. Philippot and B. Chaudret, Angew. Chem., Int. Ed., 2011, 50, 12080; (b) E. A. Baquero, S. Tricard, J. C. Flores, E. de Jesús and B. Chaudret, Angew. Chem., Int. Ed., 2014, 53, 13220.

7 E. Ramirez, L. Eradès, K. Philippot, P. Lecante and B. Chaudret, Adv. Funct. Mater., 2007, 17, 2219.

8 S. Kinayyigit, P. Lara, P. Lecante, K. Philippot and B. Chaudret, Nanoscale, 2014, 6, 539.

9 J. S. Bradley, J. M. Millar, E. W. Hill and S. Behal, J. Catal., 1991, 129, 530.
10 F. Novio, K. Philippot and B. Chaudret, Catal. Lett., 2010, $140,1$.

11 (a) L. A. Truflandier, I. Del Rosal, B. Chaudret, R. Poteau and I. C. Gerber, ChemPhysChem, 2009, 10, 2939; (b) T. Gutmann, E. Bonnefille, H. Breitzke, P.-J. Debouttiere, K. Philippot, R. Poteau, G. Buntkowsky and B. Chaudret, Phys. Chem. Chem. Phys., 2013, 15, 17383.

12 L. Cusinato, L. M. Martinez-Prieto, B. Chaudret, I. del Rosal and R. Poteau, Nanoscale, 2016, 8, 10974.

13 C. Taglang, L. M. Martinez-Prieto, I. del Rosal, L. Maron, R. Poteau, K. Philippot, B. Chaudret, S. Perato, A. Sam Lone, C. Puente, C. Dugave, B. Rousseau and G. Pieters, Angew. Chem., Int. Ed., 2015, 54, 10474.

14 (a) D. González-Gálvez, P. Lara, O. Rivada-Wheelaghan, S. Conejero, B. Chaudret, K. Philippot and P. W. N. M. van Leeuwen, Catal. Sci. Technol., 2013, 3, 99; (b) C. Richter, K. Schaepe, F. Glorius and B. J. Ravoo, Chem. Commun., 2014, 50, 3204; (c) A. Ferry, K. Schaepe, P. Tegeder, C. Richter, K. M. Chepiga, B. J. Ravoo and F. Glorius, ACS Catal., 2015, 5, 5414; (d) L. M. Martínez-Prieto, A. Ferry, P. Lara, C. Richter, K. Philippot, F. Glorius and B. Chaudret, Chem.-Eur. J., 2015, 21, 17495; (e) I. Cano, M. J. L. Tschan, L. M. Martinez-Prieto, K. Philippot, B. Chaudret and P. W. N. M. van Leeuwen, Catal. Sci. Technol., 2016, 6, 3758; (f) I. Cano, A. M. Chapman, A. Urakawa and P. W. N. M. van Leeuwen, J. Am. Chem. Soc., 2014, 136, 2520; $(g)$ I. Cano, M. A. Huertos, A. M. Chapman, G. Buntkowsky, T. Gutmann, P. B. Groszewicz and P. W. N. M. van Leeuwen, J. Am. Chem. Soc., 2015, 137, 7718.

15 (a) E. Schmidt, A. Vargas, T. Mallat and A. Baiker, J. Am. Chem. Soc., 2009, 131, 12358; (b) B. Sheng, L. Hu, T. Yu, X. Cao and H. Gu, RSC Adv., 2012, 2, 5520; (c) I. Lee and F. Zaera, Top. Catal., 2013, 56, 1284-1298.

16 (a) P. Lara, A. Suarez, V. Colliere, K. Philippot and B. Chaudret, ChemCatChem, 2014, 6, 87; (b) P. Lara and K. Philippot, Catal. Sci. Technol., 2014, 4, 2445.

17 (a) A. R. Ali, H. Ghosh and B. K. Patel, Tetrahedron Lett., 2010, 51, 1019; (b) S. Resch, A.-R. Schneider, R. Beichler, M. B. M. Spera, J. Fanous, D. Schollmeyer and S. R. Waldvogel, Eur. J. Org. Chem., 2015, 2015, 933.

18 (a) P.-J. Debouttiere, Y. Coppel, A. Denicourt-Nowicki, A. Roucoux, B. Chaudret and K. Philippot, Eur. J. Inorg. Chem., 2012, 2012, 1229; (b) P. Lara, M.-J. Casanove, P. Lecante, P.-F. Fazzini, K. Philippot and B. Chaudret, J. Mater. Chem., 2012, 22, 3578.

19 P. Lara, L. M. Martínez-Prieto, M. Roselló-Merino, C. Richter, F. Glorius, S. Conejero, K. Philippot and B. Chaudret, NanoStructures \& Nano-Objects, 2016, 6, 39.

20 M. Zahmakiran, K. Philippot, S. Oezkar and B. Chaudret, Dalton Trans., 2012, 41, 590.

21 M. Guerrero, Y. Coppel, N. T. T. Chau, A. Roucoux, A. Denicourt-Nowicki, E. Monflier, H. Bricout, P. Lecante and K. Philippot, ChemCatChem, 2013, 5, 3802.

22 F. Novio, D. Monahan, Y. Coppel, G. Antorrena, P. Lecante, K. Philippot and B. Chaudret, Chem.-Eur. J., 2014, 20, 1287. 
23 (a) F. Dassenoy, K. Philippot, T. Ould Ely, C. Amiens, P. Lecante, E. Snoeck, A. Mosset, M.-J. Casanove and B. Chaudret, New J. Chem., 1998, 22, 703; (b) D. de Caro and J. S. Bradley, New J. Chem., 1998, 22, 1267; (c) A. Duteil, R. Queau, B. Chaudret, R. Mazel, C. Roucau and J. S. Bradley, Chem. Mater., 1993, 5, 341; (d) H. J. Krebs and H. Lueth, Appl. Phys., 1977, 14, 337.

24 (a) R. P. Eischens and W. A. Pliskin, Adv. Catal., 1958, 10, 1; (b) A. M. Bradshaw and F. M. Hoffmann, Surf. Sci., 1978, 72, 513.

25 Pt amidinate complexes: (a) N. A. Bokach, M. R. Tyan, G. G. Aleksandrov, M. Haukka and V. Y. Kukushkin, Inorg. Chem. Commun., 2009, 12, 1061; (b) D. Cornacchia, R. Z. Pellicani, F. P. Intini, C. Pacifico and G. Natile, Inorg. Chem., 2009, 48, 10800, imidazolium-amidinate ligands: ref. 5 .

26 (a) J. P. Ansermet, C. P. Slichter and J. H. Sinfelt, J. Chem. Phys., 1988, 88, 5963; (b) L. R. Becerra, C. A. Klug, C. P. Slichter and J. H. Sinfelt, J. Phys. Chem., 1993, 97, 12014; (c) Y. Tong, C. Rice, N. Godbout, A. Wieckowski and E. Oldfield, J. Am. Chem. Soc., 1999, 121, 2996; (d) Y. Tong, C. Rice, A. Wieckowski and E. Oldfield, J. Am. Chem. Soc., 2000, 122, 1123.

27 N. Kuhn, M. Steimann, G. Weyers and G. Henkel, Z. Naturforsch., B: Chem. Sci., 1999, 54, 434.

28 A. Rühling, K. Schaepe, L. Rakers, B. Vonhöeren, P. Tegeder, B. J. Ravoo and F. Glorius, Angew. Chem., Int. Ed., 2016, 55, 5856.

29 Q. Ma, H. Guo, R. G. Gordon and F. Zaera, Chem. Mater., 2011, 23, 3325.
30 NIST X-ray Photoelectron Spectroscopy Database; data compiled and evaluated by C. D. Wagner, A. V. Naumkin, A. Kraut-Vass, J. W. Allison, C. J. Powell and J. R. Rumble, http://srdata.nist.gov/xps/.

31 C. Dablemont, P. Lang, C. Mangeney, J.-Y. Piquemal, V. Petkov, F. Herbst and G. Viau, Langmuir, 2008, 24, 5832.

32 (a) F. T. Edelmann, Adv. Organomet. Chem., 2008, 57, 183; (b) F. T. Edelmann, Adv. Organomet. Chem., 2013, 61, 55.

33 CPMG was originally proposed for the observation of quadrupolar nuclei with broad resonances (QCPMG) and later adapted for nuclei of spin $1 / 2$ (i.e. ${ }^{29} \mathrm{Si}$ of silica material and ${ }^{13} \mathrm{C}$ of graphene). See ref: $(a) \mathrm{J}$. W. Wiench, V. S. Y. Lin and M. Pruski, J. Magn. Reson., 2008, 193, 233; (b) K. J. Harris, Z. E. M. Reeve, D. Wang, X. Li, X. Sun and G. R. Goward, Chem. Mater., 2015, 27, 3299.

34 I. del Rosal, F. Jolibois, L. Maron, K. Philippot, B. Chaudret and R. Poteau, Dalton Trans., 2009, 2142.

$35 \mathrm{CO}$ is formed during the synthesis of $\mathrm{Ru}$ NPs via decarbonylation of THF, ref. 4.

36 G. C. Levy and R. L. Lichter in Nitrogen-15 Nuclear Magnetic Resonance Spectroscopy, Wiley Interscience, New York, 1979.

37 K. Reuter, C. Stampfl and M. Scheffler, Handbook of Materials Modeling ab initio atomistic thermodynamics and statistical mechanics of surface properties and functions, ed. S. M. Yip, Springer, 2005, vol. 1, p. 149.

38 (a) J. Kratsch, M. Kuzdrowska, M. Schmid, N. Kazeminejad, C. Kaub, P. Ona-Burgos, S. M. Guillaume and P. W. Roesky, Organometallics, 2013, 32, 1230; (b) T. Chlupaty, Z. Padelkova, A. Lycka and A. Ruzicka, J. Organomet. Chem., 2011, 696, 2346. 